\title{
Endoscopic Endonasal Infrapetrous Transpterygoid Approach to the Petroclival Junction for Petrous Apex Chondrosarcoma: Technical Report
}

\author{
Adrian J. Maurer ${ }^{1}$ Phillip A. Bonney ${ }^{1}$ Courtney R. Iser ${ }^{1}$ Rohaid Ali $^{1}$ Jose A. Sanclement ${ }^{2,3}$ \\ Michael E. Sughrue ${ }^{1,3}$
}

${ }^{1}$ Department of Neurosurgery, University of Oklahoma Health Sciences Center, Oklahoma City, Oklahoma, United States

2 Department of Otorhinolaryngology, University of Oklahoma Health Sciences Center, Oklahoma City, Oklahoma, United States

${ }^{3}$ Oklahoma Comprehensive Brain Tumor Clinic, University of Oklahoma Health Sciences Center, Oklahoma City,

Oklahoma, United States

J Neurol Surg Rep 2015;76:e113-e116.

\begin{abstract}
Address for correspondence Michael E. Sughrue, MD, Department of Neurosurgery, University of Oklahoma Health Sciences Center, $1000 \mathrm{~N}$. Lincoln Blvd., Suite 4000, Oklahoma City, OK 73104, United States (e-mail: michael-sughrue@ouhsc.edu).
\end{abstract}

\begin{abstract}
Keywords

- endoscopic endonasal

- chondrosarcoma

- minimally invasive

- petroclival

- skull base

Chondrosarcomas of the skull base are rare tumors that present difficult management considerations due to the pathoanatomical relationships of the tumor to adjacent structures. We present the case of a 25 -year-old female patient presenting with a chondrosarcoma of the right petrous apex extending inferiorly, medial to the cranial nerves. The tumor was resected via an endoscopic endonasal infrapetrous transpterygoid approach that achieved complete resection and an excellent long-term outcome with no complications. Technical nuances and potential pitfalls of the case are discussed in depth including measures to protect the carotid artery while performing the required drilling of the skull base to access the lesion.
\end{abstract}

\section{Introduction}

Skull base chondrosarcomas are rare tumors of cartilaginous tissue arising from cellular nests of nonossified bone. The mainstay of treatment for these lesions is surgical excision along with adjuvant radiotherapy. ${ }^{1-5}$ However, several traditional surgical resection techniques such as the retrosigmoid and transcochlear approaches involve working past and around the cranial nerves posing risks such as facial nerve damage and hearing loss. ${ }^{6,7}$ By utilizing the endoscopic endonasal transpterygoid approach, the risk of damaging the cranial nerves (CNs) can be minimized. However, the extensive drilling required of this approach poses a risk to the internal carotid artery. ${ }^{8-12}$ Although there is literature describing the endoscopic endonasal infrapetrous transptery-

received

September 17, 2014

accepted

January 22, 2015

published online

April 27, 2015 goid approach for such lesions, few case reports exist demonstrating successful complete tumor resection using this technique. ${ }^{13,14}$ Here we present the case of a 25 -yearold patient diagnosed with chondrosarcoma within the right petroclival junction treated successfully via the endoscopic endonasal infrapetrous transpterygoid approach. We subsequently discuss the technical nuances of utilizing such an approach.

\section{History and Examination}

A 25-year-old woman was referred to an otologist in June 2013 for right ear pain and a lesion of the external auditory canal. Computed tomography (CT) of the head demonstrated an irregular lytic lesion within the right
License terms

Stuttgart · New York

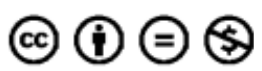


petrous bone abutting the petroclival junction ( - Fig. 1A, B). Subsequent magnetic resonance imaging demonstrated a septated, variably enhancing lesion within the right temporal base, inferomedial to the petrous carotid and anteromedial to the CN VII/VIII complex ( $\mathbf{- F i g . ~ 1 C - F ) . ~ S e v e r a l ~ s u r g i c a l ~ a p - ~}$ proaches were contemplated. A transtemporal approach was undesirable due to intact CN VII/VIII. A retrosigmoid approach was felt to be unsuitable because the lesion was medial to these nerves. A middle anterior fossa transpetrosal was not believed to provide low enough access to the lesion below the internal auditory canal. Accordingly, an endoscopic endonasal infrapetrous transpterygoid approach was planned.

\section{Operation}

The patient was positioned supine with the head placed in a Mayfield head clamp, rotated slightly contralateral to the position of the surgeon, and the image guidance system was registered. After lateralizing the middle and inferior turbinates, a left-sided septal flap pedicled on the sphenopalatine artery was separated from the mucoperichondrium until reaching the sphenoid rostrum, at which point it was tucked into the nasopharynx for later repair of the skull base. Posterior septectomy, complete ethmoidectomy, and middle turbinectomy were then performed. The right sphenopalatine artery was cauterized and the surrounding mucosa removed for further exposure. At this point, it became necessary to drill further down the crest of the posterior nasal septum to gain appropriate working angles.

The basivertebral fascia and tissue were removed to uncover the clivus. The medial pterygoid plate was drilled through laterally while utilizing image guidance to accurately determine the location of the internal carotid artery (ICA) and the lesion. The vidian nerve and canal were used as landmarks in identifying the general location of the carotid. Doppler ultrasound was also used to help confirm its location. To gain better access to the lesion inferior to the petrous carotid, the eustachian tube was freed by bluntly dissecting the surrounding soft tissue and ligamentous attachments and gently depressing the tube downward in a C-shaped fashion. Torus tubarius was also skeletonized and retracted inferiorly to allow entry through the pharyngeal recess (Rosenmüller fossa). Once the petroclival junction was exposed, it was drilled until the lesion was reached. A Kerrison punch was utilized to expand the opening of the foramen lacerum, which allowed the mass to be removed piecemeal with ring curettes. The Coblator device (ArthroCare, Austin, Texas, United States) was used to cauterize any residual tumor cells to prevent reoccurrence.

\section{Postoperative Outcome}

Postoperatively the patient did very well, and she was discharged the following day. Postoperative imaging
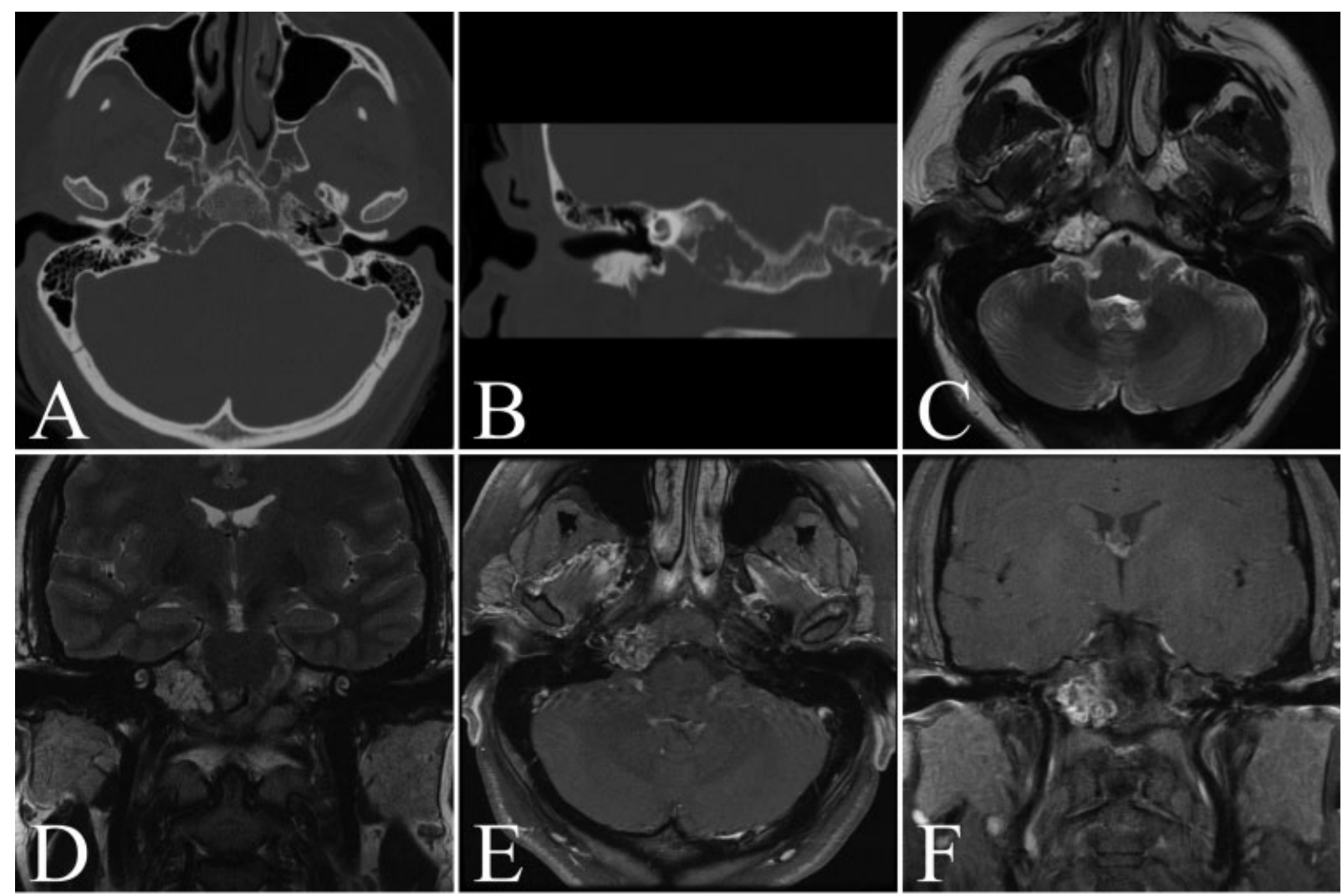

Fig. 1 Preoperative imaging. (A, B) Computed tomography scan demonstrated an erosive lesion at the petroclival junction. (C, D) Magnetic resonance imaging demonstrated hyperintensity on T2-weighted sequences and $(E, F)$ enhancement following gadolinium administration on T1-weighted sequences (E,F). 
revealed complete resection (-Fig. 2 ). She has had no cerebrospinal fluid leak, infection, or eustachian tube dysfunction. Extended follow-up has demonstrated a wellhealed repair of the sphenoid sinus. The patient underwent proton-beam radiation with a boost to the tumor bed, receiving a total of $68.55 \mathrm{~Gy}$ equivalents over 38 sessions as adjuvant therapy for her tumor. To date, now $>10$ months, she has had no evidence of recurrence and her neurologic examination is normal.

\section{Discussion and Technical Nuances}

The location of this chondrosarcoma presented unique management challenges in the access and resection of the lesion. ${ }^{1,15}$ Specifically, because the tumor was entirely medial to the cranial nerves and inferomedial to the petrous and lacerum sections of the internal carotid, the approach selection required balancing a tradeoff of risk. In a retrosigmoid approach, the carotid is protected within its course through the temporal bone, but the middle and lower CNs are directly within the path of approach to the lesion. Working between these nerves for a lesion that extends so caudally would put the patient, who had normal CN function, at risk of damage to the facial nerve, vestibulocochlear nerve, and the lower CNs. ${ }^{6}$

Similarly, a transtemporal approach, although providing a wide exposure to the more rostral portions of the petroclival junction, obviously sacrifices hearing on that side. ${ }^{7}$ In a patient presenting with complete hearing loss, this approach would be a reasonable choice. However, the skeletonization of the petrous ICA is not without risk, and the inferior portions of this tumor preclude access through a traditional transtemporal approach. That is, it would require extensive caudal drilling that may not expose the lesion in its entirety. Angled endoscopes may be of utility in such a situation, but in this patient, who had normal hearing, sacrifice of the hearing apparatus was unwarranted.

The risk in an endoscopic endonasal infrapetrous transpterygoid approach is primarily to the petrous and lacerum portions of the internal carotid. ${ }^{8,11}$ Critical to exposing the petroclival junction safely, first and foremost, is adequate exposure through sinus surgery. This provides sufficient working area for drilling of the medial pterygoid plate and allows a drilling approach from medial to lateral, thereby keeping the carotid segments protected as much as possible. Knowledge of the anatomy of the region is critical for the approach. The vidian nerve is identified within the pterygopalatine fossa and followed posteriorly, where it leads to the carotid. Drilling underneath the vidian canal will then give the approximate position of the carotid. Unless necessary, we do not expose the carotid. Doppler ultrasound is pivotal and used whenever the location of the carotid's location is uncertain. Although not exact, this tool indicates if the carotid
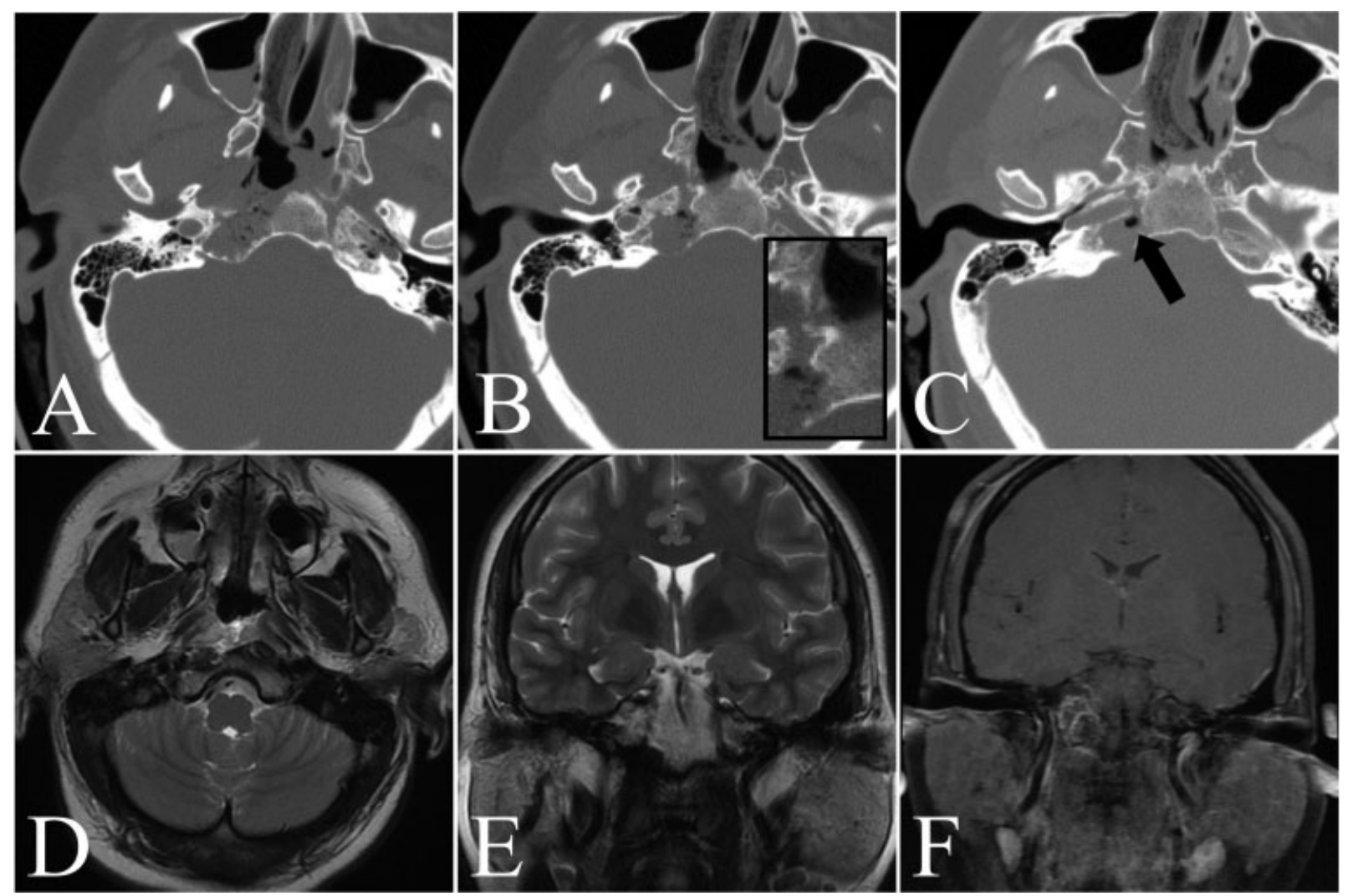

Fig. 2 Postoperative imaging. (A-C) Ascending axial sections on postoperative computed tomography scan demonstrate the infrapetrous approach corridor created by drilling. Inset in (B) shows higher magnification of bony corridor. Arrow in (C) points to a bubble of air just posterior to the internal carotid artery (ICA), highlighting the reach obtained by the approach. (D, E) T2-weighted and (F) postgadolinium T1-weighted magnetic resonance images indicate complete resection. 
is very near. We recommend liberal use of this tool during this portion of the operation. Lastly, we use image guidance fused to CT angiography with the ICA highlighted. This further enhances the safety of bony drilling. With these adjuncts the risk of injury to the carotid is low. However, in the event of possible injury we would be prepared to harvest muscle to place on the injured artery.

The eustachian tube is skeletonized by using a blunt dissector to remove soft tissue. Electrocautery must be avoided that would lead to scarring of the tube. Once these attachments are removed, inferolateral retraction is carefully performed to allow more efficient access to the pharyngeal recess (Rosenmüller fossa), through which the most direct access to the petroclival junction is attained.

Continued drilling of the medial pterygoid plate leads to foramen lacerum, which is easily identified by its cartilaginous structure. ${ }^{15}$ The foramen lacerum must be opened widely with extreme care, noting at all times the course of the carotid above the foramen. Once it is opened, the petroclival fissure is easily identified, and the lesion can be safely resected while staying cognizant of the superior location of the lacerum section of the carotid. Angled endoscopes were not needed in this case, although if a lesion were to extend laterally along the petrous face, 30 - or 70 -degree endoscopes could be utilized to ensure complete resection.

\section{Conclusion}

The choice of approach for a lesion arising from the petrous apex inferior to the carotid requires a thoughtful analysis of the risks and benefits inherent to each. Tradeoffs include the relative protection of $\mathrm{CNs}$ VII and VIII versus the protection of the ICA. When the lesion is medial to the cranial nerves and neurologic function is normal, working windows afforded by a retrosigmoid approach are inadequate to ensure gross total resection. An endoscopic endonasal infrapetrous transpterygoid technique approaching the petroclival junction through the retropterygoid space is quite feasible in carefully selected cases. Intraoperative neuronavigation and Doppler ultrasound are essential tools to protect the internal carotid through its petrous and lacerum segments; once the foramen lacerum is opened widely, tumor debulking may proceed by staying inferomedial to it. Caudal mobilization of the eustachian tube is necessary for adequate superoinferior working angles and is tolerated well.

\section{References}

1 Oghalai JS, Buxbaum JL, Jackler RK, McDermott MW. Skull base chondrosarcoma originating from the petroclival junction. Otol Neurotol 2005;26(5):1052-1060

2 Amichetti M, Amelio D, Cianchetti M, Enrici RM, Minniti G. A systematic review of proton therapy in the treatment of chondrosarcoma of the skull base. Neurosurg Rev 2010;33(2): 155-165

3 Amichetti M, Cianchetti M, Amelio D, Enrici RM, Minniti G. Proton therapy in chordoma of the base of the skull: a systematic review. Neurosurg Rev 2009;32(4):403-416

4 Crockard HA, Steel T, Plowman N, et al. A multidisciplinary team approach to skull base chordomas. J Neurosurg 2001;95(2): 175-183

5 Koutourousiou M, Snyderman CH, Fernandez-Miranda J, Gardner PA. Skull base chordomas. Otolaryngol Clin North Am 2011;44(5): 1155-1171

6 Mamikoglu B, Esquivel CR, Wiet RJ. Comparison of facial nerve function results after translabyrinthine and retrosigmoid approach in medium-sized tumors. Arch Otolaryngol Head Neck Surg 2003;129(4):429-431

7 Mason E, Van Rompaey J, Carrau R, Panizza B, Solares CA. Anatomical and computed tomographic analysis of the transcochlear and endoscopic transclival approaches to the petroclival region. Laryngoscope 2014;124(3):628-636

8 Gardner PA, Tormenti MJ, Pant H, Fernandez-Miranda JC, Snyderman $\mathrm{CH}$, Horowitz MB. Carotid artery injury during endoscopic endonasal skull base surgery: incidence and outcomes. Neurosurgery 2013;73(2, Suppl Operative):ons261-ons269; discussion ons269-ons 270

9 Cappabianca P, Cavallo LM, Esposito F, De Divitiis O, Messina A, De Divitiis E. Extended endoscopic endonasal approach to the midline skull base: the evolving role of transsphenoidal surgery. Adv Tech Stand Neurosurg 2008;33:151-199

10 Zada G, Du R, Laws ER Jr. Defining the "edge of the envelope": patient selection in treating complex sellar-based neoplasms via transsphenoidal versus open craniotomy. J Neurosurg 2011; 114(2):286-300

11 Zanation AM, Snyderman CH, Carrau RL, Gardner PA, Prevedello $\mathrm{DM}$, Kassam AB. Endoscopic endonasal surgery for petrous apex lesions. Laryngoscope 2009;119(1):19-25

12 Zhang Q Kong F, Yan B, Ni Z, Liu H. Endoscopic endonasal surgery for clival chordoma and chondrosarcoma. ORL J Otorhinolaryngol Relat Spec 2008;70(2):124-129

13 Hofstetter CP, Singh A, Anand VK, Kacker A, Schwartz TH. The endoscopic, endonasal, transmaxillary transpterygoid approach to the pterygopalatine fossa, infratemporal fossa, petrous apex, and the Meckel cave. J Neurosurg 2010;113(5):967-974

14 Schaberg MR, Evans JJ, Rosen MR. Endoscopic approaches to the petrous apex. Oper Tech Otolaryngol-Head Neck Surg 2011;22(4): 269-273

15 Feng K, Qiuhang Z, Wei Z, et al. Anatomy of the petrous apex as related to the endoscopic endonasal approach. J Clin Neurosci 2012;19(12):1695-1698 